\begin{tabular}{|c|l|}
\hline Title & Correction of Low-altitude Thermal Images applied to estimating Soil Water Status \\
\hline Author(s) & Sugiura, R.; Noguchi, N.; Ishii, K. \\
\hline Citation & $\begin{array}{l}\text { Biosystems Engineering, 96(3), 301-313 } \\
\text { https://doi.org/10.1016j.biosystemseng.2006.11.006 }\end{array}$ \\
\hline Issue Date & $2007-03$ \\
\hline Doc URL & http://hdl.handle.net/2115/22084 \\
\hline Type & article (author version) \\
\hline File Information & BE96-3.pdf \\
\hline
\end{tabular}

Instructions for use 


\title{
Correction of Low Altitude Thermal Images Applied to Estimating Soil Water Status
}

\author{
Ryo Sugiura; Noboru Noguchi; Kazunobu Ishii \\ Graduate School of Agriculture, Hokkaido University, \\ Kita-9, Nishi-9, Kita-ku, Sapporo, 060-8589, Japan; \\ e-mail of corresponding author: noguchi@bpe.agr.hokudai.ac.jp
}

\begin{abstract}
A system based on a thermal camera was development for monitoring soil water status. This study used a thermal camera to take images of a field from a low-altitude helicopter. Thermal infrared energy captured by cameras tends to include errors because of atmospheric effects. This means that the image must be corrected for atmospheric transmissivity. The transmissivity can be determined from the ambient temperature, the humidity and the distance between the target object and the sensor. A method for correcting the image was developed using a principle of thermal imaging. The imaging accuracy was improved by the correction method. Remote sensing experiments using an unmanned helicopter were conducted at an agricultural field. The experimental field was a paddy field with uniform soil quality, and the images of bare soil in the field were obtained at 10 a.m. and 3 p.m. on the same day. The correlation between the thermal image temperature and soil water content was evaluated. The determination coefficient between water content and
\end{abstract}


temperature at 10 a.m. was 0.69 and that at 3 p.m. was 0.64 . The difference in temperature between the two images was examined. The determination coefficient between water content and temperature difference was 0.42. Finally, a map of ground surface water content was generated using the captured image obtained at 10 a.m. The thermal imagery was found to be useful in determining within-field variability in ground surface soil moisture status.

\section{Notation}

$d \quad$ distance between the thermal camera and the object, $\mathrm{m}$

$E_{a} \quad$ reflection energy of ambient heat, $\mathrm{W}$

$E_{c} \quad$ thermal infrared energy corrected for emissivity and transmissivity, W

$E_{o} \quad$ thermal infrared energy emitted from an object, W

$E_{r} \quad$ uncorrected thermal infrared energy, W

$E_{S} \quad$ thermal infrared energy received by the thermal camera, W

$E_{S}{ }^{\prime} \quad$ thermal infrared energy processed internally by the thermal camera, W

$f \quad$ function that converts temperature to energy

G function that provides transmissivity

$h \quad$ relative humidity, $\%$

$h_{\text {alt }} \quad$ altitude of the helicopter above the ground, $\mathrm{m}$

$\boldsymbol{p} \quad$ transformed point of image data, $\mathrm{m}$ 
$\mathbf{Q} \quad$ rotation matrix for angles of pan-head rotation

$\boldsymbol{R}$ rotation matrix for roll, pitch and yaw angles of helicopter

S spectral response of the thermal camera, \%

$t \quad$ temperature, ${ }^{\circ} \mathrm{C}$

$t_{a} \quad$ ambient temperature, ${ }^{\circ} \mathrm{C}$

$t_{c} \quad$ temperature corrected for emissivity and transmissivity, ${ }^{\circ} \mathrm{C}$

$t_{o} \quad$ object temperature, ${ }^{\circ} \mathrm{C}$

$t_{r} \quad$ temperature measured by the thermal camera, ${ }^{\circ} \mathrm{C}$

$u, v \quad$ image coordinate, pixel

$\bar{u}, \bar{v} \quad$ resolution of the thermal camera, pixel

W spectral radiation energy, $\mathrm{W} \mathrm{cm}^{-2} \mu \mathrm{m}^{-1}$

$\mathrm{X} \quad$ axis defined in a test field for line profiling

$x_{H}, y_{H}, z_{H} \quad$ image data position in the helicopter coordinate system, $\mathrm{m}$

$x_{L}, y_{L}, z_{L} \quad$ image data position in the local coordinate system, $\mathrm{m}$

$\Delta t \quad$ temperature correction value, ${ }^{\circ} \mathrm{C}$

$\varepsilon \quad$ emissivity

$\lambda \quad$ wavelength, $\mu \mathrm{m}$

$\mu \quad$ angle of view of the thermal camera, deg

$\rho_{1}, \rho_{2}$ rotation angles of the pan-head, deg

$\tau \quad$ transmissivity

$\phi, \theta, \psi$ roll, pitch and yaw angles of the helicopter, deg 


\section{Introduction}

Thermal imaging is a non-destructive technique for sensing infrared energy radiating from the object surface (Varith et al., 2001). The energy is converted by the camera into imagery. Whereas a thermocouple or a thermistor measures temperature as spot data, a thermal image provides spatially distributed temperature of an observed area. Thermal cameras have been used to measure crop canopy temperature and to detect water stress of crops in agricultural fields (Smith et al., 1989; Wanjura et al., 2004; Yuan et al., 2004; Luquet et al., 2004). The use of thermal imagery for detecting water stress is based on the observation that evaporation cools a plant leaves almost to air temperature, and sometimes below air temperature, as the crop transpires through stomata (Luquet et al., 2003). And thus canopy temperature correlates with water stress of the crop. Aircraft- or satellite-based sensors offer information of large spatial scale. This provides the opportunity to extract great amounts of ground-surface data. In one study, spectral emissivity was extracted from the thermal image data collected by aircraft-based remote sensing system and a surface mineral map was generated (Vaughan et al., 2005). Gómez et al. (2005) showed evapotranspiration imagery generated from airborne-captured thermal imagery. The water temperature of a river has been measured by airborne imaging (Torgersen et al., 2001). Thermal infrared information obtained by satellite-based remote sensing has been used to classify land surface properties (Park et al., 2004; Dousset et al., 2003) and to monitor the environment (Clark, 1993; Tran et al., 2006). The error caused by atmospheric effects must be identified for interpretation of remotely sensed data (Price, 1983; Kahle et al., 1984). 
Thermal infrared radiant energy decreases depending on atmospheric transmissivity (Maul, 1983). As the hand-held camera used in this study was also a remote sensing device, the correction of imagery was needed to acquire useful data. The images suffered from the effects of transmissivity, effects that differed depending on ambient temperature, humidity and distance from the object to the sensor. In this study, a method that corrects for atmospheric transmissivity was developed and the post-correction measurement accuracy was examined.

This study focuses on monitoring the soil water status in an agricultural field. Conventional methods of measuring soil water content in an agricultural field are spot measuring, such as by soil sampling, and time domain reflectometry (TDR). In spot measuring, the spatial variability of water status is represented by the spot data. However, the spatial variability of the field cannot be expressed properly by spot measurement, due to poor spatial resolution. Image-based remote sensing can solve this problem, and it is very effective for monitoring water status. Many studies on remote sensing have addressed determination of water status of the ground surface. A near-infrared laser mounted on an aircraft has been used to estimate water status of the ground surface (Kobayashi et al., 2005). The reflected light intensity of near-infrared laser correlated with the soil water content. This result was based on the fact that the near-infrared band is the absorption band of water. Some studies have estimated water status by using thermal inertia derived from remotely sensed imagery (Pratt \& Ellyett, 1979; Verhoef, 2004). Thermal inertia is the heat storage capacity calculated from the temporal temperature difference (Abrams et al., 1984; Price, 1985). The thermal inertia determines the temperature behaviour, and it increases 
with soil water content. It is widely known that thermal inertia or specific heat of soil is very useful for estimating the soil water status. The use of thermal imagery can be very effective for estimating the spatial variability of soil water status because the temperature imagery instantly provides information for a large spatial area. The recognition of spatial variability in soil water status or drainage quality in agricultural fields is a key factor in site-specific agricultural field management (Corwin \& Plant, 2005; Corwin \& Lesch, 2005; Wraith et al., 2005; Earl et al., 2003). However, aircraft- or satellite-based sensors have the problem of low spatial resolution when monitoring the spatial variability of small agricultural fields such as paddy fields in Japan. Thermal infrared data with high spatial resolution is desired for observation of within-field variability.

Sugiura et al. (2005) developed an unmanned helicopter-based remote sensing system by equipping an unmanned helicopter with a global positioning system (GPS) and an inertial navigation sensor (INS). This system can obtain image data of a field at low altitude and can generate a high-resolution field map in the global coordinate system by integrating the GPS and INS data. The objective of the present research is to develop a helicopter-based remote sensing system that uses a thermal camera to monitor soil water status in an agricultural field. A camera was mounted on a helicopter to obtain images of bare soil in an agricultural field. A model for estimating soil water content was developed, and a water content map of the agricultural field was generated. 


\section{Temperature measurement by the thermal camera}

\subsection{Specifications of the thermal camera}

The thermal camera used in this research can measure the surface temperature of an object by sensing infrared radiation in the 8 to $14 \mu \mathrm{m}$ wavelength range. As this camera has a two-dimensional CCD array, the measured surface temperature is the output as an image. The dynamic range of the temperature is from -20 to $100{ }^{\circ} \mathrm{C}$. The image resolution is $320 \times 240$ pixels and the diagonal angle of view is $65^{\circ}$. The image is saved to a memory card in the camera. The temperature data saved by the camera have a resolution of 14 bits/pixel. The camera was mounted on an unmanned helicopter. An adjustable pan-head was installed in the helicopter to control the attitude of the sensor (Sugiura et al., 2005). The pan-head can be controlled in the pan and tilt directions. Encoders measure rotation angles on each of two axes of rotation.

\subsection{Principle of thermal imaging}

The spectral response of the camera, denoted by $S$ in \%, is shown in Fig. 1. The function $f$ for converting temperature into thermal infrared energy was determined as follows:

$$
f(t)=\int_{8}^{14} W(\lambda, t) S(\lambda) d \lambda
$$

Where: $W$ is the spectral energy in $\mathrm{Wcm}^{-2} \mu \mathrm{m}^{-1}$ emitted from a black body, $\lambda$ is the wavelength in $\mu \mathrm{m}$.

Figure 2 shows the basic principle of the thermal infrared measurement. An object whose emissivity is $\varepsilon$ radiates the emissive energy $E_{o}$ and reflected energy $E_{a}$ of ambient 
heat. These two types of energy in $\mathrm{W}$ can be expressed by the following equations.

$$
\begin{aligned}
& E_{o}=\varepsilon f\left(t_{o}\right) \\
& E_{a}=(1-\varepsilon) f\left(t_{a}\right)
\end{aligned}
$$

where: $t_{o}$ is the temperature of the target object and $t_{a}$ is the ambient temperature in ${ }^{\circ} \mathrm{C}$. Considering the transmissivity $\tau$ of the air between the camera and the object, the energy that reaches the camera, $E_{S}$ in $\mathrm{W}$ is

$$
\begin{aligned}
E_{S} & =\tau\left(E_{o}+E_{a}\right) \\
& =\tau\left\{\varepsilon f\left(t_{o}\right)+(1-\varepsilon) f\left(t_{a}\right)\right\} \\
& =\tau \varepsilon\left\{f\left(t_{o}\right)-f\left(t_{a}\right)\right\}+\tau f\left(t_{a}\right)
\end{aligned}
$$

The function $\tau f\left(t_{a}\right)$ of the third equation in Eqn (3) is automatically eliminated by the internal operation of the camera. Thus, the energy $E_{S}$ changes into $E_{S}{ }^{\prime}$ in W as follows:

$$
E_{S}^{\prime}=\tau \varepsilon\left\{f\left(t_{o}\right)-f\left(t_{a}\right)\right\}
$$

Finally, the temperature of the target object can be obtained by substituting Eqn (4) into the following equation:

$$
t_{o}=f^{-1}\left\{\frac{E_{S}^{\prime}}{\varepsilon \tau}+f\left(t_{a}\right)\right\}
$$

According to the final equation (Eqn (5)), determination of the correct temperature requires the proper emissivity $\varepsilon$ and transmissivity $\tau$ to be known. However, even if these parameters are unknown, the relative variability of the temperature of the object can be recognised. If the material and texture of the object are uniform and the distances between the object and the thermal camera are the same in each pixel, the thermal image accurately expresses the relative variability of the surface temperature. 


\section{Field experiments}

\subsection{Test field and ground-truth measurement}

Field experiments were conducted on 24 April 2005 at a paddy field in Hokkaido, Japan. There were no plants in the test field when the experiments were conducted. The images were obtained at 10 a.m. and 3 p.m. in legal time on the same day. Although the test field had uniform soil quality, the drainage quality was not uniform. The test field measured 125 $\mathrm{m} \times 35 \mathrm{~m}$. The soil water content for the ground-truth data was obtained by soil sampling at the 32 points plotted in Fig. 3. Soil was sampled at around 12 a.m. on the same day as the remote sensing experiment. The depth of the soil sampling was $5 \mathrm{~cm}$ from the ground surface and one sample was obtained at each point. Soil water content was measured by oven-drying at $105^{\circ} \mathrm{C}$ for 24 hours. The measured water content ranged from 28.8 to $54.2 \%$. A line $\mathrm{X}$ that contains 21 ground-truth points was defined. Figure 4 shows the spatial variability of the water content along the line $\mathrm{X}$. The water content of west part of the field was high and that of east part was low.

\subsection{Thermal images taken from the helicopter}

The whole area should be taken in one image to acquire the spatial variability of the temperature. If the camera vertically looks to downward, an altitude greater than $120 \mathrm{~m}$ is needed to cover the whole test field in one image. It is very difficult to fly the unmanned helicopter that high. Therefore, in this study, images were taken obliquely. Figures 5(a) and 5(b) are the images taken at 10 a.m. and 3 p.m. From these, field maps of surface 
temperature were generated (Fig. 6). Both images were taken looking westward from the east side of the field at the altitude of $40 \mathrm{~m}$. It can be seen that the surface temperature of the west part is low and that of the east part is high. However, it is not evident that this spatial variability indicates the actual distribution of surface temperature. In general, remotely sensed thermal imagery suffers inaccuracy as a result of atmospheric transmissivity, and one parameter for determining the transmissivity is the distance from the camera to the object. As these two images were taken obliquely (Fig. 5), the distances between the ground surface and the camera are not uniform for each pixel. Therefore, the images must be corrected with respect to transmissivity in each pixel of the overall image.

\section{Method of correcting the thermal image}

\subsection{Acquisition of transmissivity}

The transmissivity $\tau$ can be determined from the distance $d$ in $\mathrm{m}$, ambient temperature $t_{a}$ in ${ }^{\circ} \mathrm{C}$ and humidity $h$ in \% as follows:

$$
\tau=G\left(d, t_{a}, h\right)
$$

The camera used in this research has the data table $G$ from which it determines transmissivity according to distance, air temperature and humidity. This research used the transmissivity obtained from this data table to correct the images captured from the helicopter. The data table was generated by the algorithm of moderate resolution transmittance (MODTRAN) code (Richter, 1996; Wang et al., 2002) generally used to 
calculate transmissivity. Figure 7 gives examples of changes in transmissivity at the ambient temperatures of $10^{\circ} \mathrm{C}$ and $20^{\circ} \mathrm{C}$, depending on distance and humidity. It can be seen that transmissivity decreases the greater is the distance, temperature or humidity.

\subsection{Development of correction model}

Assuming value for the emissivity $\varepsilon$ of 1.00 and for the transmissivity $\tau$ of 1.00 , the thermal image temperature $t_{r}$ in ${ }^{\circ} \mathrm{C}$ can be expressed by following equation derived from Eqn (5):

$$
t_{r}=f^{-1}\left\{E_{r}+f\left(t_{a}\right)\right\}
$$

Here, $E_{r}$ is the thermal infrared energy in W received by the camera. This energy $E_{r}$ can be obtained by the following equation:

$$
E_{r}=f\left(t_{r}\right)-f\left(t_{a}\right)
$$

The ambient temperature must be measured at the time of image acquisition. The corrected energy, denoted by $E_{c}$ in $\mathrm{W}$, is regarded as the estimated energy emitted by the object and is calculated using the following equation:

$$
E_{c}=\frac{E_{r}}{\varepsilon \tau}=\frac{f\left(t_{r}\right)-f\left(t_{a}\right)}{\varepsilon \tau}
$$

Replacing $E_{r}$ in Eqn (7) with $E_{c}$, the corrected temperature data $t_{c}$ in ${ }^{\circ} \mathrm{C}$ can be obtained as follows:

$$
t_{c}=f^{-1}\left\{E_{c}+f\left(t_{a}\right)\right\}
$$

If the true emissivity and transmissivity are known, the calculated value for $t_{c}$ is the temperature of the object. 
The characteristics of this correction model of image were explored. The difference between the temperatures of the raw image and the corrected image, (i.e., the correction value), was defined as $\Delta t$ in ${ }^{\circ} \mathrm{C}$ by the following equation:

$$
\Delta t=t_{c}-t_{r}
$$

The simulation was conducted to show the characteristics of the correction model. Figure 8 is one of the examples of image correction under the ambient temperature of $21.0^{\circ} \mathrm{C}$. The emissivity was a constant value of 1.00 , and the value for the transmissivity was changed from 0.60 to 1.00 . The correction value increased with increases in the raw image temperature and was affected by the transmissivity. The other characteristic is that the correction value becomes zero when the raw image temperature is the same as the ambient temperature. Therefore, when the raw image temperatures were $21.0^{\circ} \mathrm{C}$, the correction values were zero at any transmissivity (Fig. 8). Using this correction method, the image obtained from the helicopter can be corrected for each pixel.

\subsection{Validation of the correction method}

A basic experiment was conducted to validate the correction method mentioned above. As shown in Fig. 9(a), a board was heated until the temperature became constant. The heated board was observed by the camera while changing the distance from 0.5 to $58.0 \mathrm{~m}$ at intervals of $0.5 \mathrm{~m}$. The 116 images, each taken under a different transmissivity, were obtained. Figure 9(b) shows an image taken at the distance of $4.0 \mathrm{~m}$ as an example of the data. The parts with the highest temperature in each image were used as the test data to validate the correction model. The temperature of the heated board was measured by a 
thermocouple for comparison with the image data. The ambient temperature was $15.0^{\circ} \mathrm{C}$ and the humidity was $42 \%$. These parameters, used to determine the transmissivity, were measured by thermometer and hygrometer. During the experiment, the board temperature was almost constant, ranging from $79.4^{\circ} \mathrm{C}$ to $81.2^{\circ} \mathrm{C}$. There cannot be an object with such a high temperature in the agricultural field. However, in thermal imaging, a large error occurs for an object that has large temperature difference from the ambient air. If the object temperature is almost the same as the ambient air temperature, the error would be extremely small and it would be difficult to examine the influence of transmissivity on thermal imaging. Therefore, in this experiment, an object of about $80^{\circ} \mathrm{C}$ was used, in order to determine the error of thermal imaging.

First, the image obtained at the distance of $0.5 \mathrm{~m}$ was used to determine the emissivity of the board. The error in the image is caused by emissivity and transmissivity. However, as the value for transmissivity $\tau$ is almost 1.00 at a distance of $0.5 \mathrm{~m}$, the influence of the transmissivity can be ignored. Hence, the emissivity $\varepsilon$ in Eqn (9) was adjusted such that the error of thermal image temperature would be zero, and the actual value for emissivity was determined as 0.96. All images were corrected for emissivity and transmissivity, which were determined using the distance, the ambient temperature and the humidity. Under this condition, the transmissivity decreased from 1.00 to 0.88 with increasing distance. Figure 10 shows the error of the thermal image temperature. The negative error increases depending on the distance. Because the temperature of the object exceeded the ambient temperature, the thermal image temperature was lower than the actual temperature. The error in the image at the distance of $20 \mathrm{~m}$ was $-4.7^{\circ} \mathrm{C}$ and that at $50 \mathrm{~m}$ was $-7.3^{\circ} \mathrm{C}$. This 
error caused by transmissivity was eliminated by the correction method. The root mean square (RMS) error over 116 images was $0.7^{\circ} \mathrm{C}$, and the RMS error of the 17 images taken at distances from $50 \mathrm{~m}$ to $58 \mathrm{~m}$ was $1.2^{\circ} \mathrm{C}$. The measurement accuracy was greater with correction than without, thereby demonstrating the validity of this method.

\section{Water content estimation results and discussion}

\subsection{Corrected thermal images}

Distance between the camera and the ground surface, $d$ was one of the parameters to determine transmissivity (Eqn (6)). Since the helicopter-based remote sensing system provided the position and posture of the camera, the distance $d$ can be calculated as shown in Fig. 11 (Sugiura et al., 2005). The image coordinate in pixels $(u, v)$ defined in the UV system [Fig. 11(a)] is converted to a point $\left[\begin{array}{lll}x_{H} & y_{H} & z_{H}\end{array}\right]^{\mathrm{T}}$ in the helicopter coordinate system $\left(\mathrm{X}_{\mathrm{H}} \mathrm{Y}_{\mathrm{H}} \mathrm{Z}_{\mathrm{H}}\right)$ in $\mathrm{m}$ as follows [Fig. 11(b)]

$$
\begin{aligned}
& x_{H}=u-\bar{u} / 2 \\
& y_{H}=\bar{v} / 2-v \\
& z_{H}=-\sqrt{(\bar{u} / 2)^{2}+(\bar{v} / 2)^{2}} / \tan (\mu / 2)
\end{aligned}
$$

where: $\bar{u}$ and $\bar{v}$ are the resolution of the image in pixels, (i.e., $\bar{u}=320$ and $\bar{v}=240$ ). $\mu$ is the angle of view in degree of the camera. The local coordinate system $\left(X_{L} Y_{L} Z_{L}\right)$ was defined such that its origin would equal the optical origin of the sensor, as shown in Fig. 11(c). The point $\left[\begin{array}{lll}x_{H} & y_{H} & z_{H}\end{array}\right]^{\mathrm{T}}$ can be transformed into $\left[\begin{array}{lll}x_{L} & y_{L} & z_{L}\end{array}\right]^{\mathrm{T}}$ in the $\mathrm{X}_{\mathrm{L}} \mathrm{Y}_{\mathrm{L}} \mathrm{Z}_{\mathrm{L}}$ system by using the rotation matrices $\boldsymbol{R}$ and $\boldsymbol{Q}$, expressed by 


$$
\left[\begin{array}{l}
x_{L} \\
y_{L} \\
z_{L}
\end{array}\right]=\boldsymbol{R}(\phi, \theta, \psi) \boldsymbol{Q}\left(\rho_{1}, \rho_{2}\right)\left[\begin{array}{l}
x_{H} \\
y_{H} \\
z_{H}
\end{array}\right]
$$

where: $\phi, \theta$ and $\psi$ are the roll, pitch and yaw angles in degrees of the helicopter; and $\rho_{1}$ and $\rho_{2}$ are the pan and tilt rotation angles in degrees of the adjustable pan-head. If $h_{a l t}$ is the helicopter altitude in $\mathrm{m}$ from the ground, the transformed image data position, denoted by $\boldsymbol{p}$ in $\mathrm{m}$, can be obtained by

$$
\boldsymbol{p}=-\frac{h_{\text {alt }}}{z_{L}}\left[\begin{array}{c}
x_{L} \\
y_{L} \\
z_{L}
\end{array}\right]
$$

Therefore, the distance $d$ can be calculated as the norm of the position vector $\boldsymbol{p}$ as follows:

$$
d=|\boldsymbol{p}|
$$

Figure 12(a) shows a corrected image taken at 10 a.m. This image was taken under the ambient temperature of $7.3^{\circ} \mathrm{C}$ and the humidity of $58 \%$. The ambient temperature and the humidity, measured by thermometer and hygrometer at the ground level, were assumed constant from the soil surface up to the helicopter. The transmissivity for correcting this image is shown in Fig. 12(b). The distance from the camera to the near side of the field was $72 \mathrm{~m}$ and the transmissivity corresponding to this distance was 0.88 . The distance to the far side of the field was $188 \mathrm{~m}$, and the transmissivity was 0.83 . Figure $13(a)$ is the corrected image taken at 3 p.m., and Fig. 13(b) is the transition of transmissivity under the conditions of that time. The corrected images do not indicate the actual temperature of the ground surface, because the emissivity of the soil was not considered. However, correction for emissivity was not needed, because the soil quality of the test field was uniform. Therefore, 
these images express the relative spatial variability of the actual temperature.

\subsection{Soil water content estimation}

Figures 14(a) and 14(b) show thermal infrared maps drawn using the corrected images. Furthermore, Fig. 14(c) shows the difference in temperature of the two images. It can be seen that the temperature of the eastern part of the field differs considerably between morning and afternoon. This research examined the correlation between soil water content and thermal image temperature. The data on line $\mathrm{X}$ shown in Fig. 3 were considered. The line profiles of $\mathrm{X}$ in each map were extracted as shown in Fig. 15. Negative correlations between soil water content and ground surface temperature can be seen in Figs. 15(a) and 15(b). In contrast, a positive correlation between soil water content and the difference in temperature between the two images can be seen in Fig. 15(c). The area with low water content had a large temporal change in temperature. The temperature in the area with high water content did not change much. Generally, the specific heat and the thermal inertia of the soil become high with increasing water content. Accordingly, the behavior of soil temperature becomes less sensitive with increasing soil water content. This can explain the relation between soil water content and the data extracted from the maps by the line profiles. The correlations between thermal image temperature and soil water content using 32 ground-truth data are shown in Fig. 16. The coefficients of determination of the images obtained at 10 a.m. and 3 p.m. were 0.69 , 0.67, respectively, and the difference in temperature between the two images was 0.42 . This research used the image of 10 a.m. to estimate water content and to generate the water content map. Figure 17 shows the map of 
estimated water content. It is clear that this map provides the spatial variability of water content with high resolution.

\section{Conclusions}

A system that can generate a map of soil water content was developed using the thermal camera. This study introduced a model for correction of transmissivity. Basic experiments were conducted to evaluate that model. Temperature could be measured within a $0.7^{\circ} \mathrm{C}$ of RMS error when applying the correction model. The remote sensing was conducted at a paddy field whose soil is uniform in quality. The images for water content estimation were taken at 10 a.m. and 3 p.m. the same day. When the raw images were used, the determination coefficient between thermal image temperature at 10 a.m. and water content was 0.64 and that between temperature at $3 \mathrm{p} . \mathrm{m}$. and water content was 0.62 . On the other hand, determination coefficients were improved to $0.69,0.67$, respectively when the correction method was applied. In this research, the image taken at 10 a.m. was used to generate a map of soil water content, because that image had the highest correlation between temperature and water content. Because emissivity of soil surface can not be measured by this system, it needs to be calibrated with ground-truth data at each time remote sensing is conducted. However, the water content correlated with the surface temperature and could be estimated by linear-regression with thermal image temperature. It was concluded that the approach of using thermal imagery was very useful for estimation of 
soil water status in an agricultural field.

\section{References}

Abrams M J; Kahle A B; Palluconi F D; Schieldge J P (1984). Geologic mapping using thermal images. Remote Sensing of Environment, 16(1), 13-33

Clark C D (1993). Satellite remote sensing for marine pollution investigations. Marine Pollution Bulletin, 26(7), 357-368

Corwin D L; Lesch S M (2005). Characterizing soil spatial variability with apparent soil electrical conductivity: I. Survey protocols. Computers and Electronics in Agriculture, 46(1-3), 103-133

Corwin D L; Plant R E (2005). Applications of apparent soil electrical conductivity in precision agriculture. Computers and Electronics in Agriculture, 46(1-3), 1-10

Dousset B; Gourmelon F (2003). Satellite multi-sensor data analysis of urban surface temperatures and landcover. ISPRS Journal of Photogrammetry and Remote Sensing, 58(1-2), 43-54

Earl R; Taylor J C; Wood G A; Bradley I; James I T; Waine T; Welsh J P; Godwin R J; Knight S M (2003). Soil Factors and Their Influence on Within-field Crop Variability, Part I: Field Observation of Soil Variation. Biosystems Engineering, 84(4), 425-440

Gómez M; Olioso A; Sobrino J A; Jacob F (2005). Retrieval of evapotranspiration over the Alpilles/ReSeDA experimental site using airborne POLDER sensor and a thermal 
camera. Remote Sensing of Environment, 96(3-4), 30, 399-408

Kahle A B; Schieldge J P; Alley R E (1984). Sensitivity of thermal inertia calculations to variations in environmental factors. Remote Sensing of Environment, 16(3), 211-232

Kobayashi N; Yamashiro Y; Nishikawa T (2005). Characteristics and an example of airborne laser scanner (in Japanese). Journal of the Society of Irrigation, Drainage and Reclamation Engineering, 73(6), 491-492.

Luquet D; Bégué A; Vidal A; Clouvel P; Dauzat J; Olioso A; Gu X F; Tao Y (2003). Using multidirectional thermography to characterize water status of cotton. Remote Sensing of Environment, 84(3), 411-421

Luquet D; Vidal A; Dauzat J; Bégué A; Olioso A; Clouvel P (2004). Using directional TIR measurements and 3D simulations to assess the limitations and opportunities of water stress indices. Remote Sensing of Environment, 90(1), 53-62

Maul G A (1983). Zenith angle effects in multichannel infrared sea surface remote sensing. Remote Sensing of Environment, 13(5), 439-451

Park S, Feddema J J; Egbert S L (2004) Impacts of hydrologic soil properties on drought detection with MODIS thermal data. Remote Sensing of Environment, 89(1), 53-62

Pratt D A; Ellyett C D (1979). The thermal inertia approach to mapping of soil moisture and geology. Remote Sensing of Environment, 8(2), 151-168

Price J C (1983). Estimating surface temperatures from satellite thermal infrared data-A simple formulation for the atmospheric effect. Remote Sensing of Environment, 13(4), $353-361$

Price J C (1985). On the analysis of thermal infrared imagery: The limited utility of 
apparent thermal inertia. Remote Sensing of Environment, 18(1), 59-73

Richter R (1996). Atmospheric correction of DAIS hyperspectral image data. Computers \& Geosciences, 22(7), 785-793

Smith R C G; Prathapar S A; Barrs H D; Slavich P (1989). Use of a thermal scanner image of a water stressed crop to study soil spatial variability. Remote Sensing of Environment, 29(2), 111-120

Sugiura R; Noguchi N; Ishii K (2005). Remote-sensing Technology for Vegetation Monitoring Using an Unmanned Helicopter. Biosystems Engineering, 90(4), 369-379

Torgersen C E; Faux R N; McIntosh B A; Poage N J; Norton D J (2001). Airborne thermal remote sensing for water temperature assessment in rivers and streams. Remote Sensing of Environment, 76(3), 386-398

Tran H; Uchihama D; Ochi S; Yasuoka Y (2006). Assessment with satellite data of the urban heat island effects in Asian mega cities. International Journal of Applied Earth Observation and Geoinformation, 8(1), 34-48

Varith J; Hyde G M; Baritelle A L; Fellman J K; Sattabongkot T (2001). Thermal Image Bruise Detection, ASAE Paper No. 016031

Vaughan R G; Hook S J; Calvin W M; Taranik J V (2005). Surface mineral mapping at Steamboat Springs, Nevada, USA, with multi-wavelength thermal infrared images. Remote Sensing of Environment, 99(1-2), 140-158

Verhoef A (2004). Remote estimation of thermal inertia and soil heat flux for bare soil. Agricultural and Forest Meteorology, 123(3-4), 221-236

Wang P; Liu K Y; Cwik T; Green R (2002). MODTRAN on supercomputers and parallel 
computers. Parallel Computing, Volume 28(1), 53-64

Wanjura D F; Maas S J; Winslow J C; Upchurch D R (2004). Scanned and spot measured canopy temperatures of cotton and corn. Computers and Electronics in Agriculture, 44(1), 33-48

Wraith J M; Robinson D A; Jones S B; Long D S (2005). Spatially characterizing apparent electrical conductivity and water content of surface soils with time domain reflectometry. Computers and Electronics in Agriculture, 46(1-3), 239-261

Yuan G; Luo Y; Sun X; Tang D (2004). Evaluation of a crop water stress index for detecting water stress in winter wheat in the North China Plain. Agricultural Water Management, 64(1), 29-40 


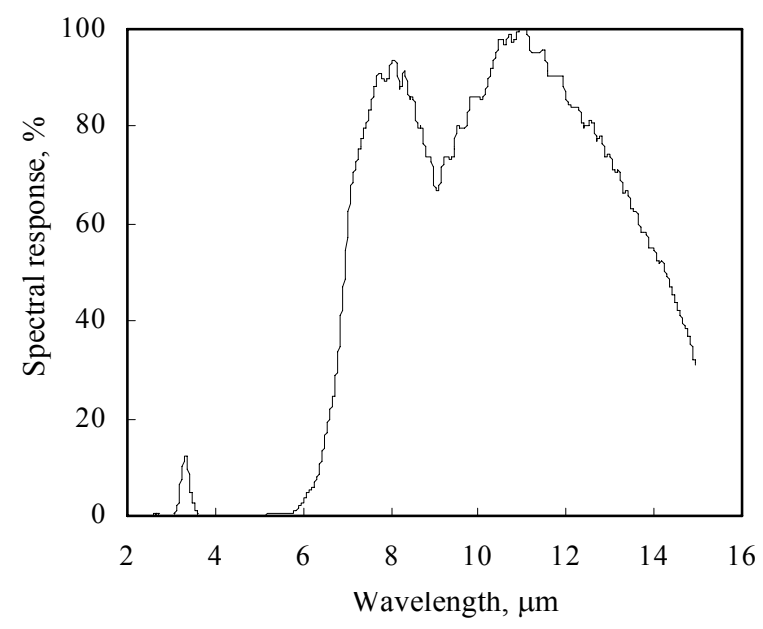

Fig. 1. Spectral response of the thermal camera 


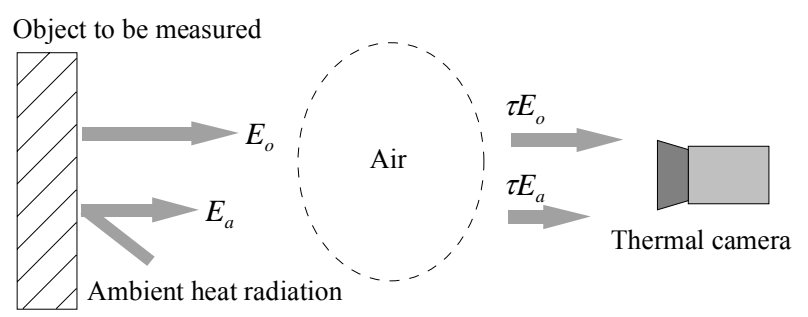

Fig. 2. Components of energy radiating from an object and the principle of the thermal imaging: $E_{o}$, emission energy of the object; $E_{a}$, reflection energy of ambient heat radiation; $\tau$, transmissivity of the air 


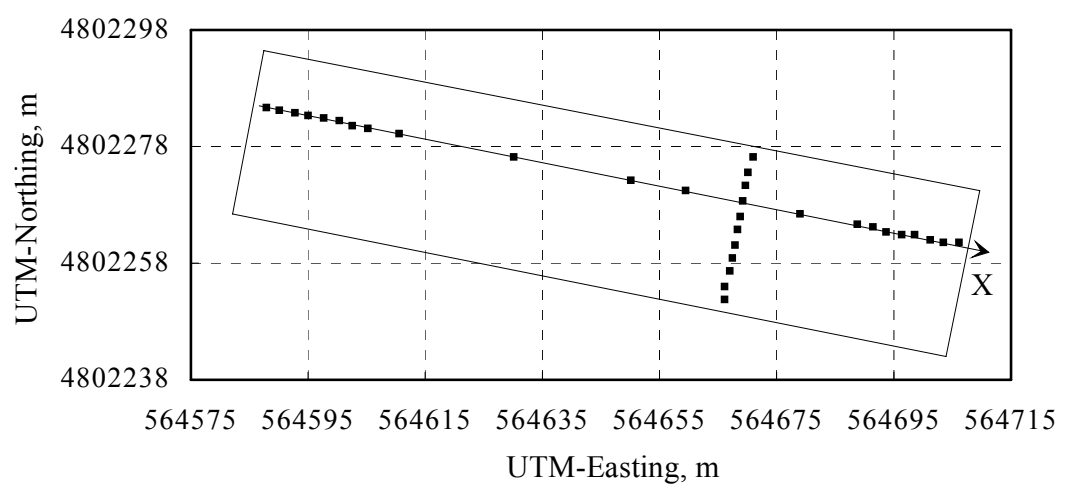

Fig. 3. Experimental field (-) and ground-truth points ( $\mathbf{\square})$ : X, local axis defined in the experimental field; UTM, universal transverse Mercator 


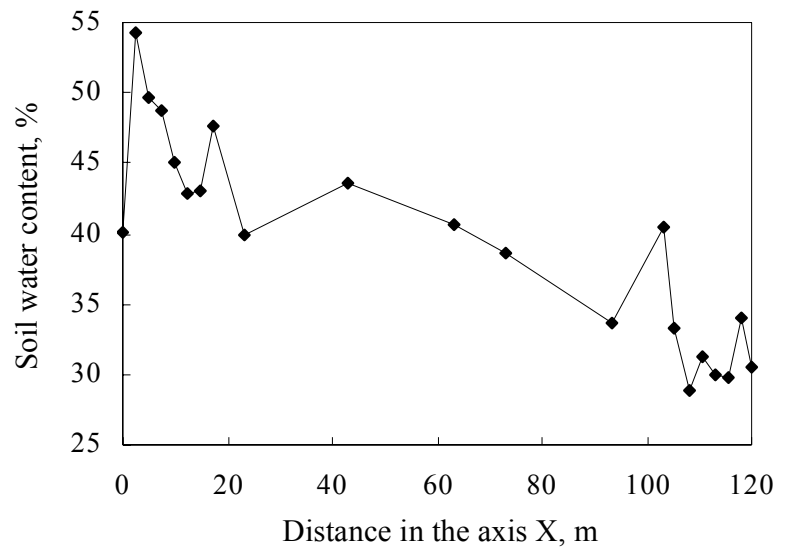

Fig. 4. Spatial variability of water content in the experimental field: $X$, the local axis defined in the field 


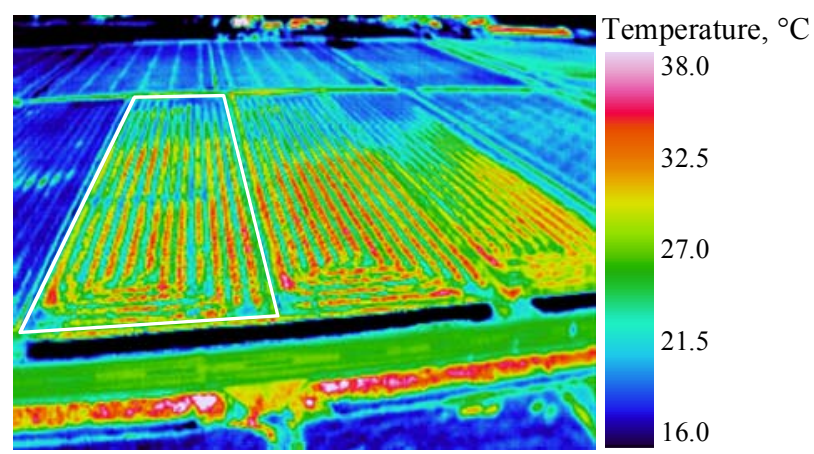

(a)

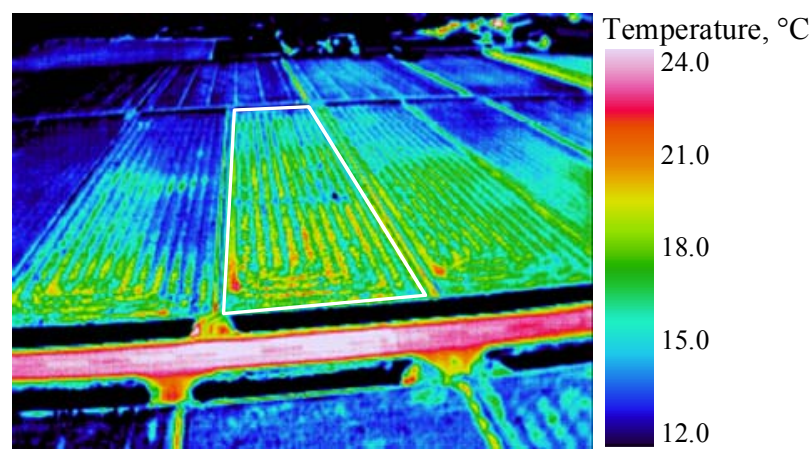

(b)

Fig. 5. Thermal images taken from the helicopter at (a) 10 a.m. and (b) 3 p.m.: the white lines shows the boundary of the experimental field 

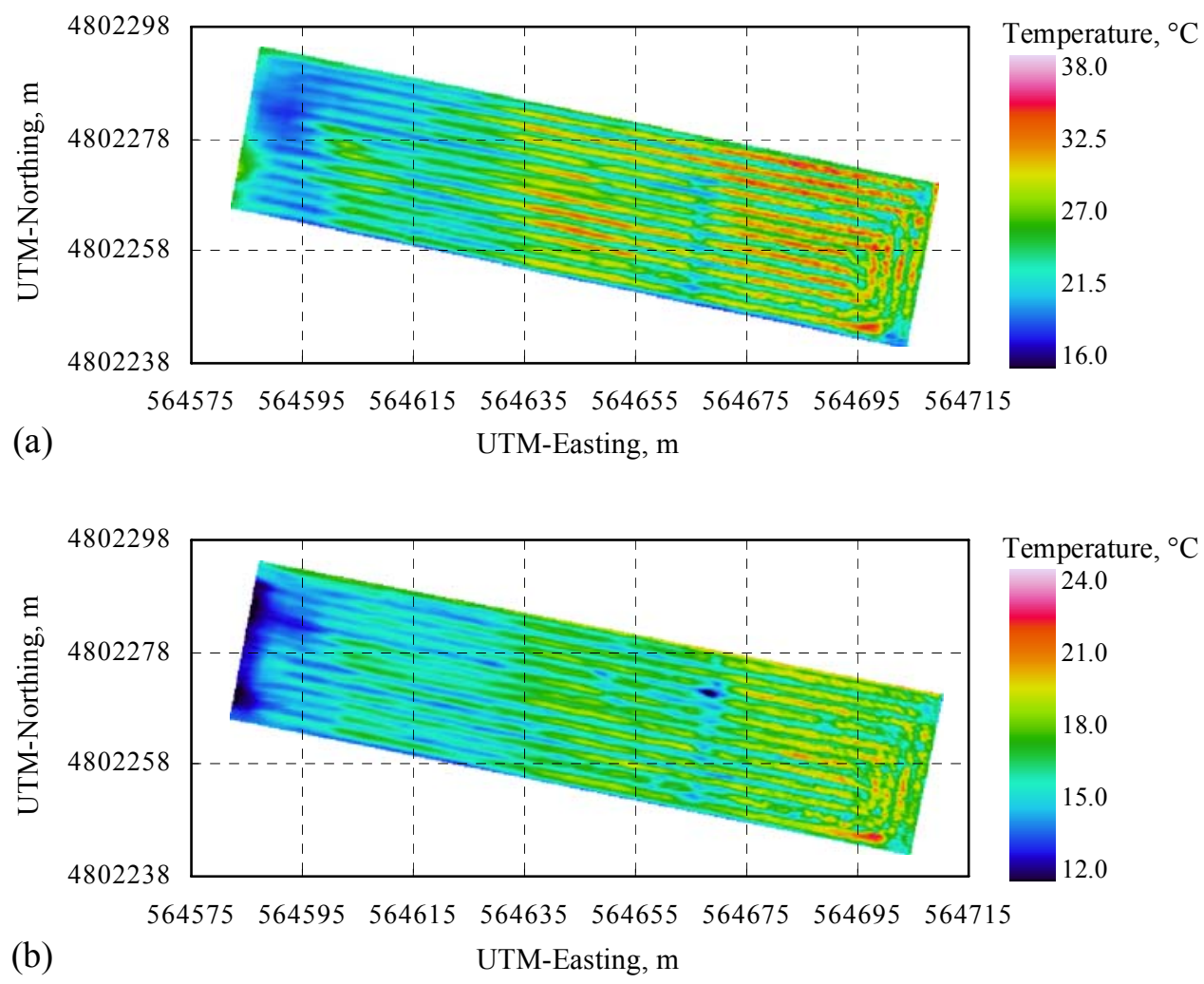

Fig. 6. Thermal image maps generated by the images of (a) Fig. 6 (a) and (b) Fig. 6(b):

UTM, universal transverse Mercator 

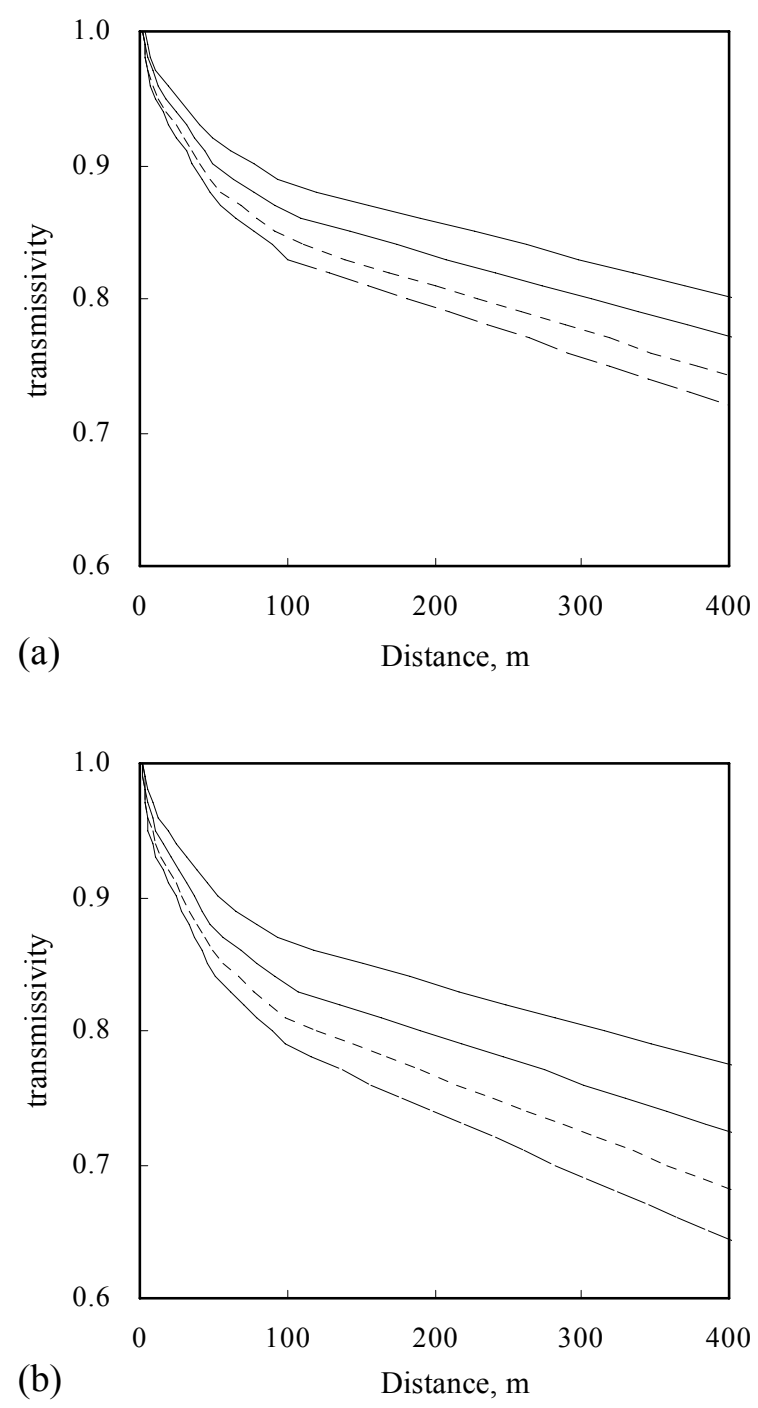

Fig. 7. Transition of transmissivity with the distance in the temperature of (a) $10^{\circ} \mathrm{C}$ and (b) $20^{\circ} \mathrm{C}$ in the humidity of $20 \%(-), 40 \%(--), 60 \%(--)$ ) and $80 \%\left(--{ }_{-}\right)$ 


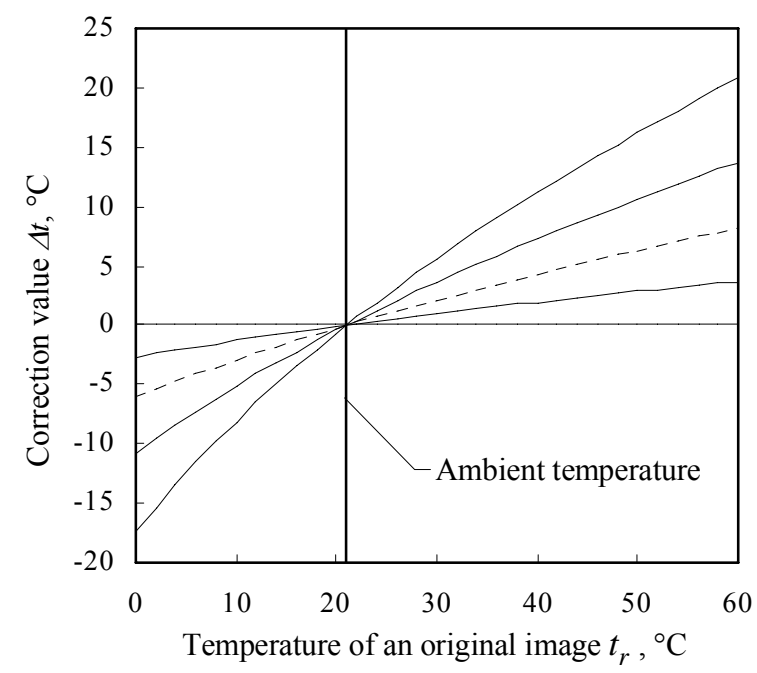

Fig. 8. Correction value with the temperature in the transmissivity of $0.6(-), 0.7$

$$
(--), 0.8(---), 0.9(--) \text { ) and } 1.0(---)
$$




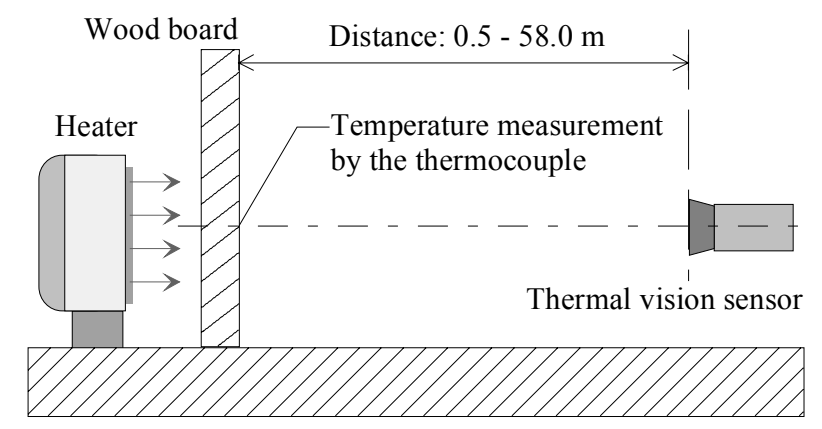

(a)

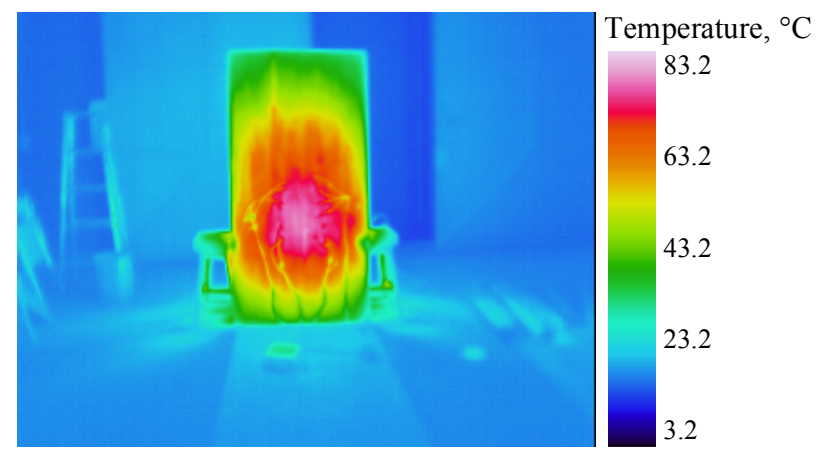

(b)

Fig. 9. (a) Experiment to evaluate temperature measurement accuracy of the thermal camera and (b) a thermal image taken at distance of $4 \mathrm{~m}$ 


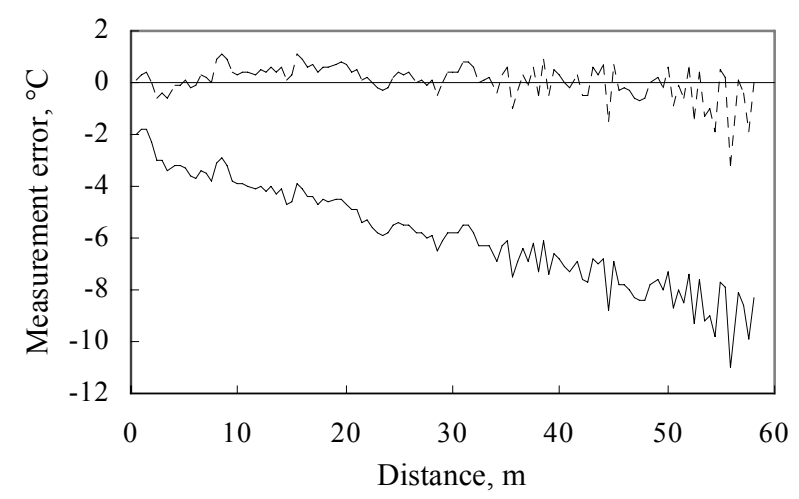

Fig. 10. Comparison of the measurement accuracy with correction (dotted line), without correction (continuous line) 


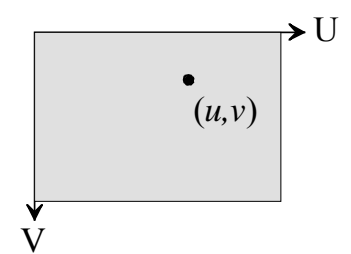

(a)

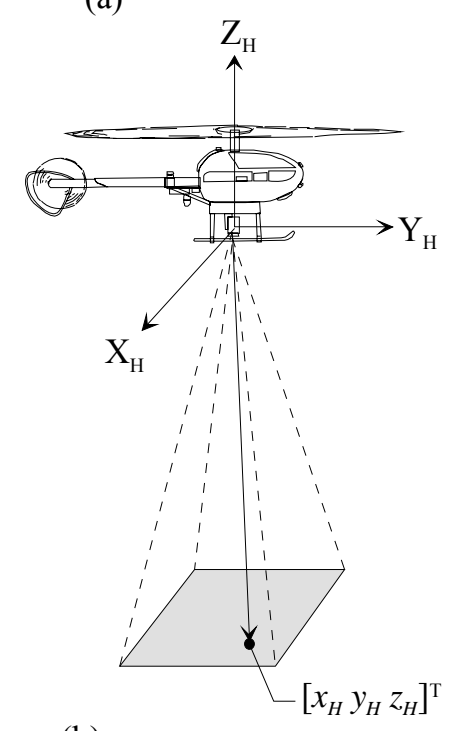

(b)

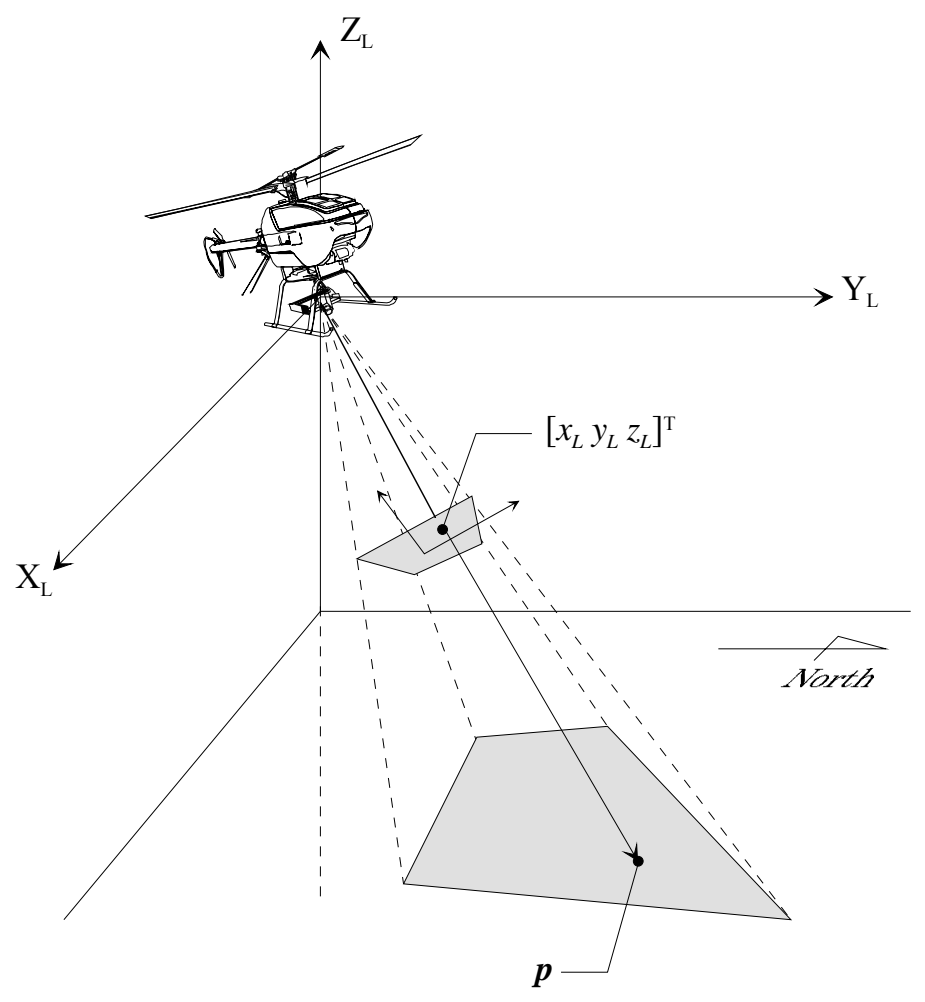

(c)

Fig. 11. Transformation method of the image data: (a), image coordinate $(u, v)$; (b), conversion from the image coordinate to the helicopter coordinate $\left[\begin{array}{lll}x_{H} & y_{H} & z_{H}\end{array}\right]^{\mathrm{T}} ;(c)$, projection of the image data to the ground surface; $\left[\begin{array}{lll}x_{L} & y_{L} & z_{L}\end{array}\right]^{\mathrm{T}}$, image data position in the local coordinate system; $\boldsymbol{p}$, image data position projected to the ground surface in the local coordinate system 


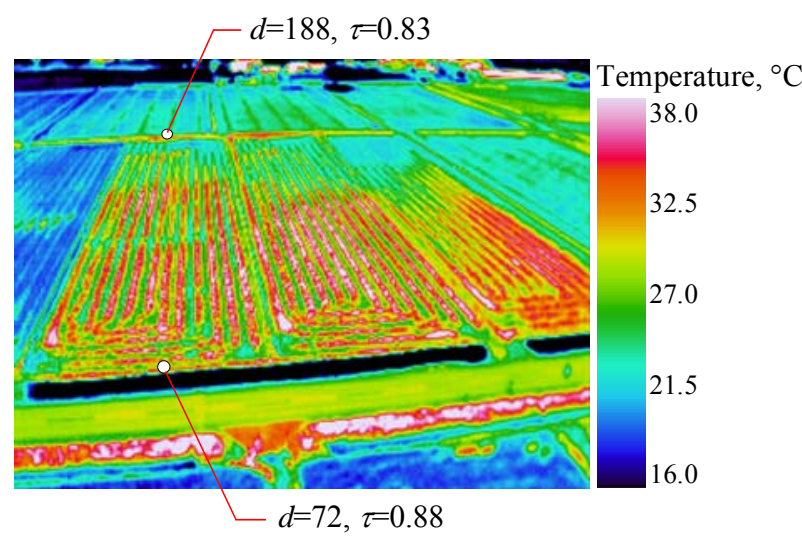

(a)

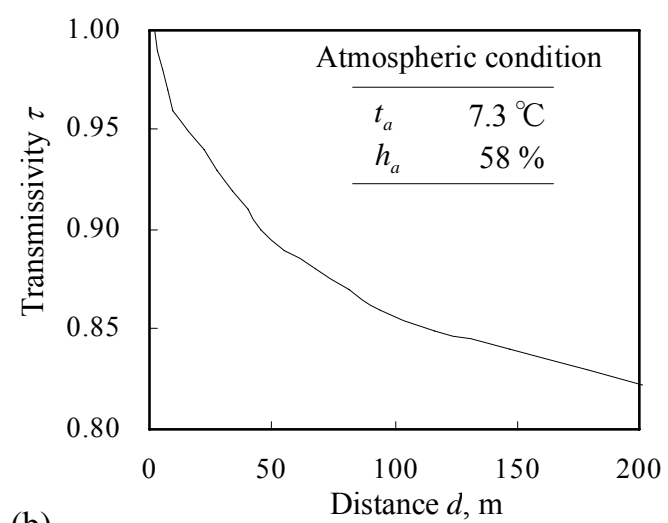

(b)

Fig. 12. Correction of the image taken at 10 a.m. and the transmissivity used for the correction: $d$, distance between the camera and the ground surface; $t_{a}$, ambient temperature; $h_{a}$, ambient humidity; $\tau$, transmissivity 

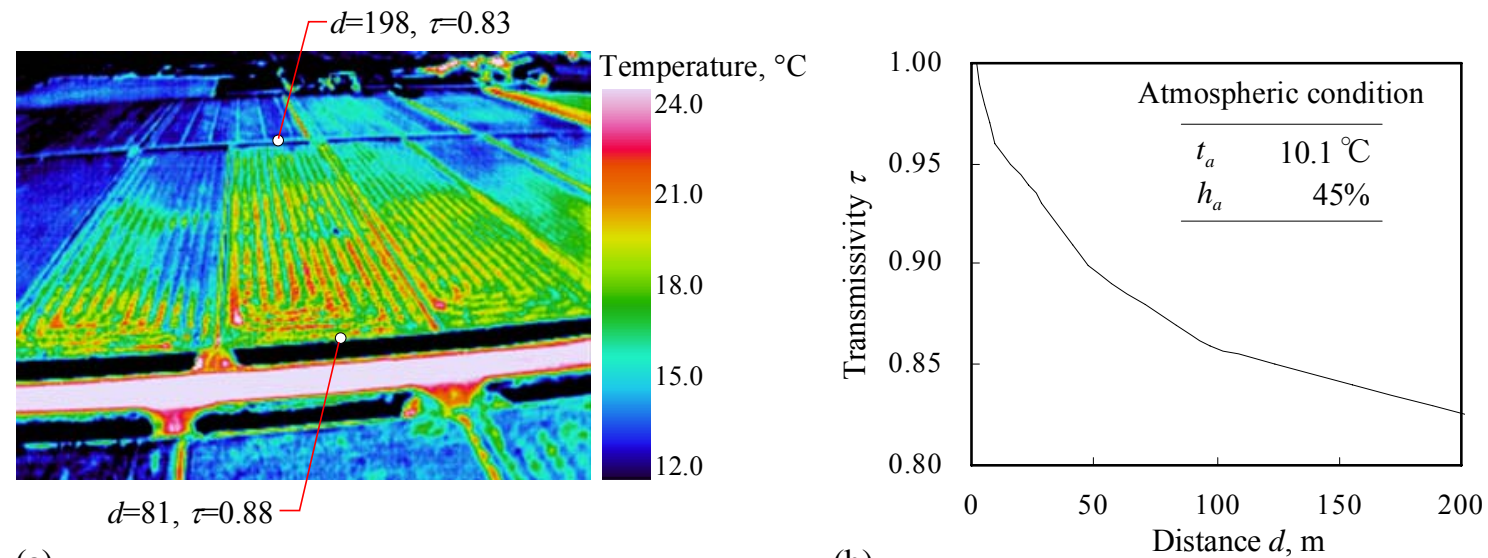

(a)

(b)

Fig. 13. Correction of the image taken at 3 p.m. and the transmissivity used for the correction: $d$, distance between the camera and the ground surface; $t_{a}$, ambient temperature; $h_{a}$, ambient humidity; $\tau$, transmissivity 


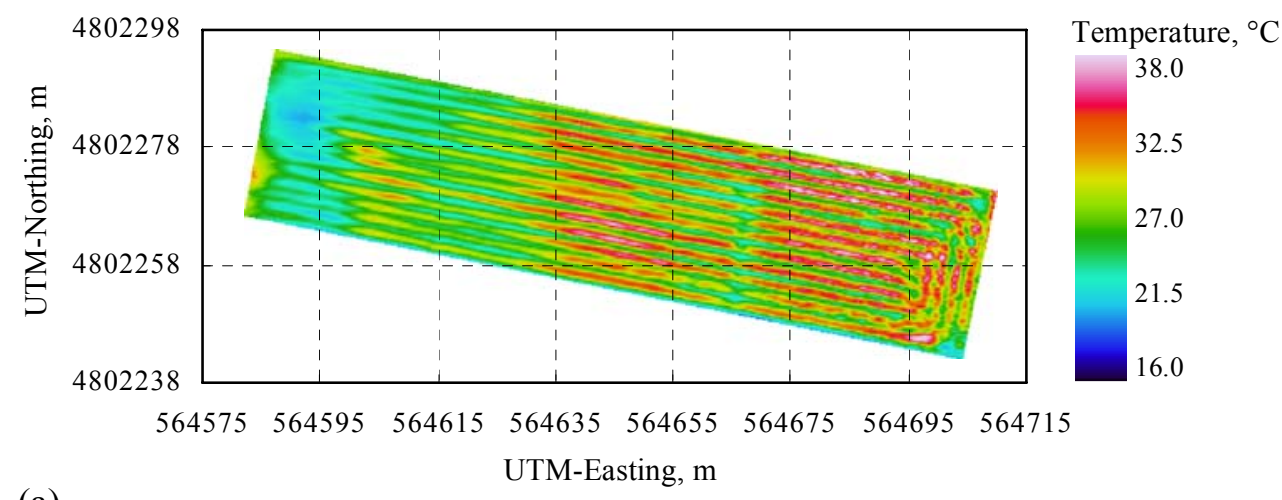

(a)

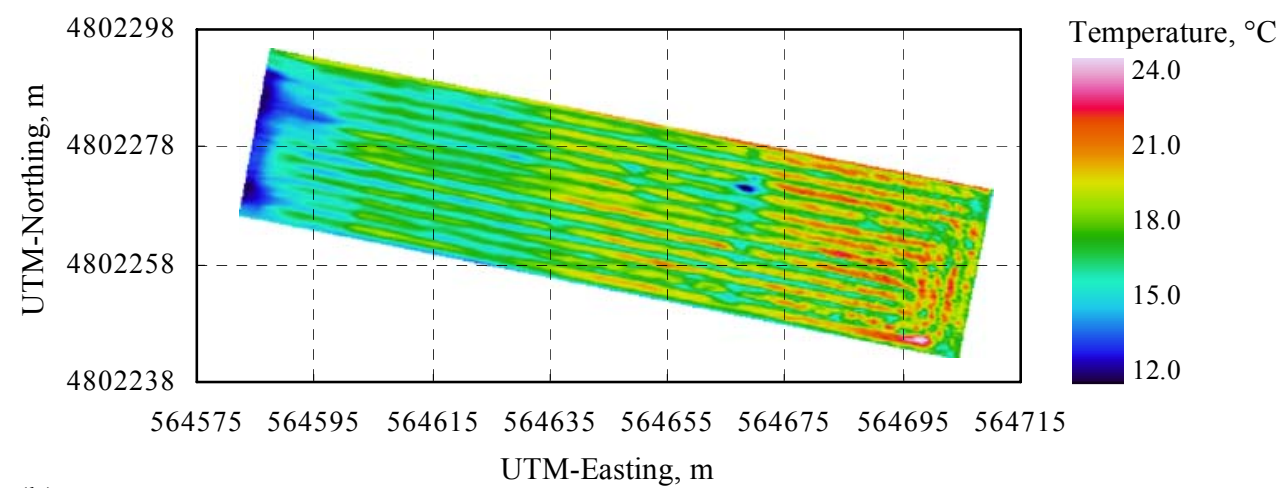

(b)

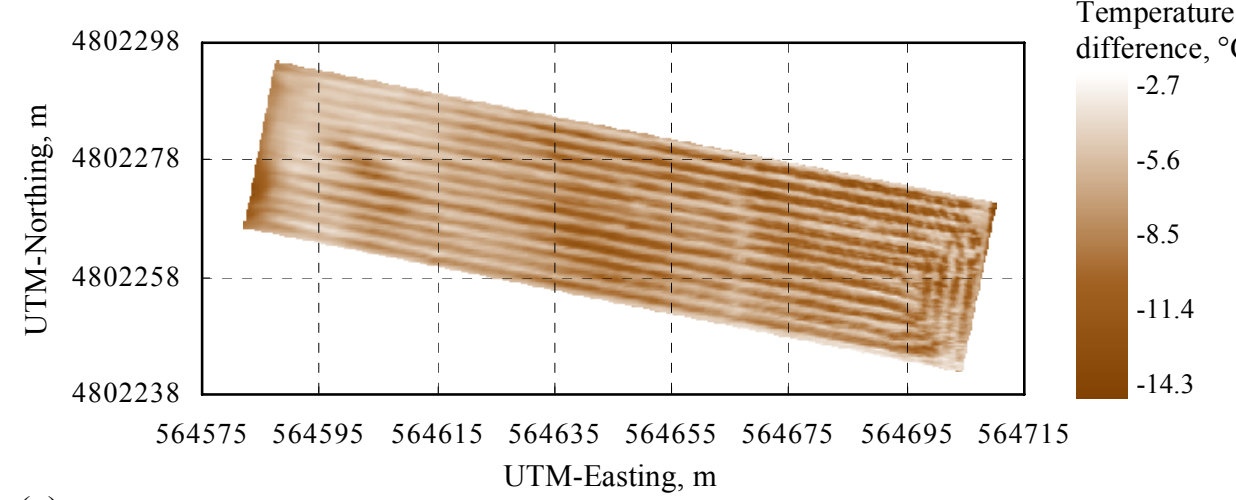

(c)

Fig. 14. Field maps generated from (a) the thermal image taken at 10 a.m., (b) at 3 p.m. and the temperature difference of the map of (b) and that of (a): UTM, universal transverse

\section{Mercator}


(a)

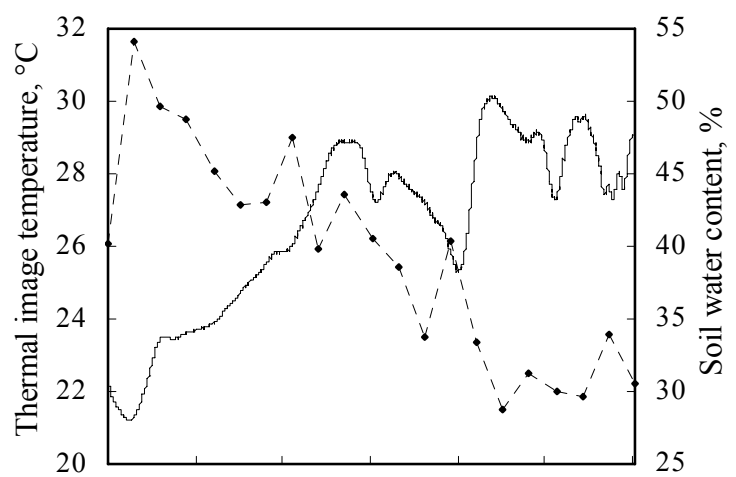

(b)
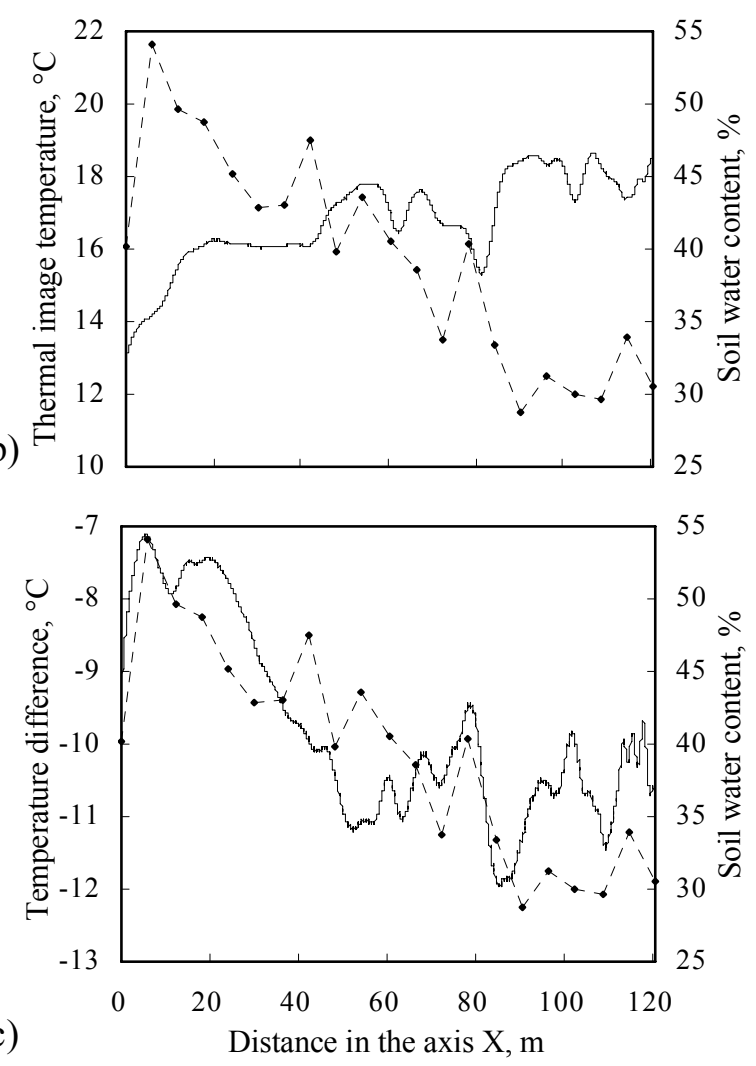

Fig. 15. Results of the line profiles of the field maps; (a) 10 a.m.; (b) 3 p.m.; (c) temperature difference of two maps; $X$, axis defined in the test field; , the data extracted from the maps by line profiling; --•--, soil water content 

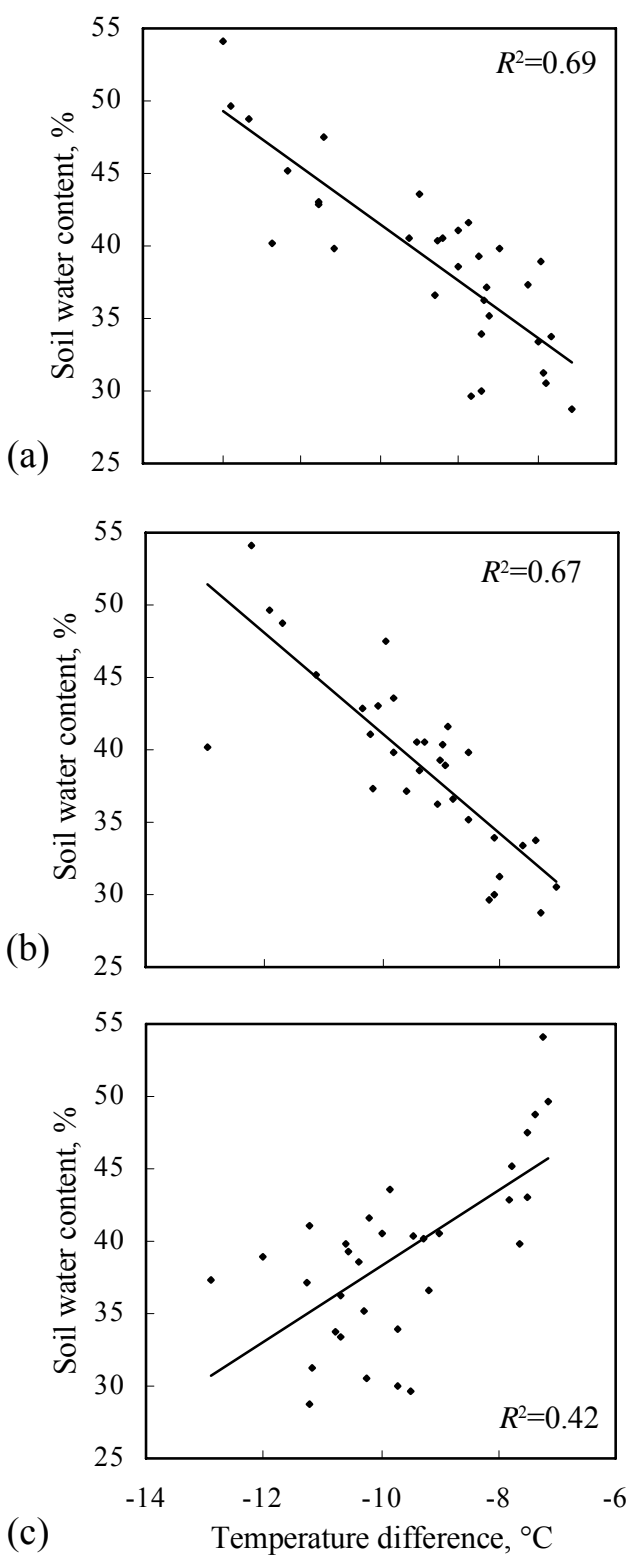

Fig. 16. Correlation between soil water content and (a) the thermal image temperature at 10 a.m., (b) the thermal image temperature at 3 p.m. and (c) the temperature difference of two maps: • the data extracted from the field maps; regression line; $R$, correlation coefficient 


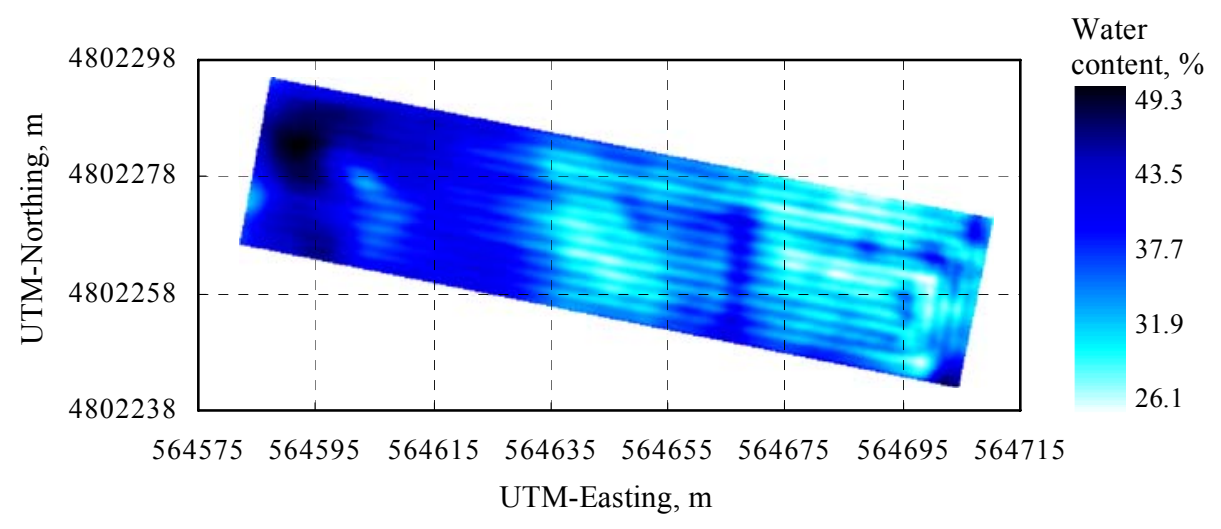

Fig. 17. Soil water content map generated from the thermal image: UTM, universal transverse Mercator 


\section{Figure captions}

Fig. 1. Spectral response of the thermal camera

Fig. 2. Components of energy radiating from an object and the principle of the thermal imaging: $E_{o}$, emission energy of the object; $E_{a}$, reflection energy of ambient heat radiation; $\tau$, transmissivity of the air

Fig. 3. Experimental field (-) and ground-truth points ( $(\mathbf{\square})$ X, local axis defined in the experimental field; UTM, universal transverse Mercator

Fig. 4. Spatial variability of water content in the experimental field: $X$, the local axis defined in the field

Fig. 5. Thermal images taken from the helicopter at (a) 10 a.m. and (b) 3 p.m.: the white lines shows the boundary of the experimental field

Fig. 6. Thermal image maps generated by the images of (a) Fig. 6 (a) and (b) Fig. 6(b): UTM, universal transverse Mercator

Fig. 7. Transition of transmissivity with the distance in the temperature of (a) $10^{\circ} \mathrm{C}$ and (b) $20^{\circ} \mathrm{C}$ in the humidity of $20 \%(-), 40 \%(--), 60 \%(---)$ and $80 \%(--)^{-}$

Fig. 8. Correction value with the temperature in the transmissivity of $0.6(-), 0.7(--)$, $0.8(---), 0.9(--)$ ) and $1.0(---)$

Fig. 9. (a) Experiment to evaluate temperature measurement accuracy of the thermal camera and (b) a thermal image taken at distance of $4 \mathrm{~m}$

Fig. 10. Comparison of the measurement accuracy with correction (dotted line), without correction (continuous line) 
Fig. 11. Transformation method of the image data: (a), image coordinate $(u, v) ;(b)$, conversion from the image coordinate to the helicopter coordinate $\left[\begin{array}{llll}x_{H} & y_{H} & z_{H}\end{array}\right]^{\mathrm{T}}$; (c), projection of the image data to the ground surface; $\left[\begin{array}{llll}x_{L} & y_{L} & z_{L}\end{array}\right]^{\mathrm{T}}$, image data position in the local coordinate system; $\boldsymbol{p}$, image data position projected to the ground surface in the local coordinate system

Fig. 12. Correction of the image taken at 10 a.m. and the transmissivity used for the correction: $d$, distance between the camera and the ground surface; $t_{a}$, ambient temperature; $h_{a}$, ambient humidity; $\tau$, transmissivity

Fig. 13. Correction of the image taken at 3 p.m. and the transmissivity used for the correction: $d$, distance between the camera and the ground surface; $t_{a}$, ambient temperature; $h_{a}$, ambient humidity; $\tau$, transmissivity

Fig. 14. Field maps generated from (a) the thermal image taken at 10 a.m., (b) at 3 p.m. and the temperature difference of the map of (b) and that of (a): UTM, universal transverse Mercator

Fig. 15. Results of the line profiles of the field maps; (a) 10 a.m.; (b) 3 p.m.; (c) temperature difference of two maps; $X$, axis defined in the test field; —- the data extracted from the maps by line profiling; -----, soil water content

Fig. 16. Correlation between soil water content and (a) the thermal image temperature at 10 a.m., (b) the thermal image temperature at 3 p.m. and (c) the temperature difference of two maps: - the data extracted from the field maps; , regression line; $R$, correlation coefficient

Fig. 17. Soil water content map generated from the thermal image: UTM, universal transverse Mercator 